\title{
O futebol no campo das pedagogias críticas: a legitimação da Educação Física escolar a partir dos elementos da cultura corporal
}

\section{Football in the field of critical pedagogies: the legitimation of school Physical Education from the elements of body culture}

\author{
José Jairo Vieira ${ }^{1 *}$, Fernando Paulo de Lima ${ }^{2}$ Shirléia dos Santos Peixoto ${ }^{2}$,
}

\section{RESUMO}

Apresentamos o conteúdo "futebol", a partir das pedagogias críticas, no contexto da Copa do Mundo de 2018, numa turma de $6^{\circ}$ ano da rede municipal do Rio. O projeto foi desenvolvido em 16 aulas, durante o segundo bimestre do ano de 2018. Esse trabalho visou mediar os conhecimentos referentes ao futebol, a partir do planejamento e sistematização das aulas, considerando-o uma manifestação corporal/cultural, ancorado na Pedagogia Histórico-Crítica (SAVIANI, 1983) e na metodologia crítico-superadora (COLETIVO DE AUTORES, 1992. A partir da contextualização do conteúdo e da preocupação com o trato pedagógico dado ao futebol, podemos citar como elementos em nossa prática pedagógica: a relevância social do futebol em nossa sociedade, a provisoriedade do conhecimento dada a historicidade dos fatos e o processo de institucionalização do futebol. As aulas de Educação Física pautadas na transformação didático-pedagógica do esporte e na participação ativa dos alunos, contribuem para a transposição de um modelo tradicional e tecnicista de ensino, caminhando rumo a legitimidade na formação humana dos alunos.

Palavras-chave: Educação fisica; Pedagogia Histórico-Crítica; cultura corporal; Futebol;

\begin{abstract}
We present the "football" content, based on critical pedagogies, in the context of the 2018 World Cup, in a 6th grade class from the municipal network of Rio. The project was developed in 16 classes, during the second quarter of 2018. This work aimed to mediate knowledge related to football, from the planning and systematization of classes, considering it a corporal/cultural manifestation, anchored in the HistoricalCritical Pedagogy (SAVIANI, 1983) and in the critical-overcoming methodology (COLETIVO DE AUTORES , 1992). From the contextualization of the content and the concern with the pedagogical treatment given to football, we can cite as elements in our pedagogical practice: the social relevance of football in our society, the provisionality of knowledge given the historicity of the facts and the process of institutionalization of the football. Physical Education classes based on the didactic-pedagogical transformation of sport and on the active participation of students, contribute to the transposition of a traditional and technical teaching model, moving towards legitimacy in the human formation of students..
\end{abstract}

Keywords: Physical Education; Historical-Critical Pedagogy; Body Culture, Soccer;

\footnotetext{
${ }^{1}$ Universidade Federal do Rio de Janeiro. *E-mail: diversidade.desigualdade.educa@gmail.com

${ }^{2}$ Secretaria Municipal de Educação do Rio de Janeiro / Universidade Federal do Rio de Janeiro
} 


\section{INTRODUÇÃO}

O processo de educação formal é de extrema relevância para uma sociedade "a ser” constituída por indivíduos críticos e capazes de transformá-la. Entendemos a escola, como aponta Taques (et. al, 2009) como espaço público e instituição responsável pela democratização do saber elaborado e sistematizado, que visa contribuir para essa transformação. A escola, nesse contexto, trabalha não apenas aproximando os alunos de uma cultura erudita, mas deve-se considerar toda a bagagem de conhecimento trazida pelos alunos, ou seja, trabalho não-material, ideias, conceitos, valores, símbolos, hábitos, atitudes, habilidades.

Saviani (1983) atribui à escola a possibilidade da troca de saberes, de professores e alunos, em seus diferentes níveis de compreensão, tanto de experiência, como de conhecimento. Nessa perspectiva, propõe melhorias profundas na formação do aluno, sendo assim a escola deve garantir a todos um ensino de qualidade e saberes básicos, e para isso acontecer e necessário uma formação de qualidade do professor, para que nesse processo de ensino-aprendizagem seja o mais proveitoso possível.

A Educação Física (EF) é uma prática pedagógica que trabalha os elementos da cultura corporal, através dos jogos e brincadeiras, esportes, lutas, ginásticas e das danças (BRACHT, 1999). Todos esses elementos têm a finalidade de propor aos alunos relações individuais, solidarias e participativas. Dessa forma, cabe ao professor proporcionar uma aprendizagem significativa, a partir de uma prática pedagógica condizente com o papel social da escola.

Dentro das modalidades esportivas, o futebol é uma manifestação cultural/corporal, criada, sistematizada e transmitida historicamente pela humanidade, que tomou forma no ambiente escolar como conteúdo da EF. O futebol, como produto cultural, alimenta a promoção de megaeventos pelo mundo, como a Copa do Mundo. Como conteúdo da EF, deve ser apropriado em suas diferentes dimensões, inclusive as que se materializam nas competições oficiais, de forma que ao ser tratado pedagogicamente nas aulas de EF contribuirá com a formação de um aluno mais preparado para refletir criticamente acerca dessa prática que é majoritária no Brasil, dentro e fora da escola. 
Entendendo que profissão docente hoje é socialmente marcada pela desvalorização, o "ser" professor da disciplina de EF é quase que uma dupla desvalorização. Isto porque a EF é uma disciplina que, historicamente, se caracterizou pela lógica do fazer, configurando-se como uma atividade não portadora de conteúdos necessários para a construção, nos dizeres de Saviani (2013), da "segunda natureza", a humanidade do sujeito.

Assim sendo, apresentamos as perguntas norteadoras desse estudo: como tematizar o futebol nas aulas de EF ancorados na pedagogia Histórico-Crítica e nos elementos da cultura corporal? Como relacionar as aulas de EF com a prática social dos alunos, tornando a aprendizagem significativa? Essa abordagem crítica do futebol pode contribuir no processo de legitimação da EF dentro da escola? Apresentamos como hipótese preliminar, que quando mediados de forma crítica e em sua totalidade, os conteúdos da EF escolar dialogam com os objetivos amplos da escola, ou seja, para a formação integral dos sujeitos.

Para respondermos às questões do estudo, traçamos os seguintes objetivos: mediar os conhecimentos referentes ao futebol, junto aos alunos das turmas de $6^{\circ}$ ano do ensino fundamental de uma escola pública municipal do Rio de Janeiro, a partir do planejamento e sistematização das aulas, considerando-o uma manifestação corporal/cultural. Promover debates e reflexões, a partir da problematização acerca dos impactos do futebol em nossa cultura e dos megaeventos em nossa sociedade. Resgatar, a partir da cultura popular e da história do futebol, jogos e brincadeiras que utilizem elementos da modalidade esportiva e que estão presentes no cotidiano desses alunos, através da metodologia críticosuperadora ancorada nos pressupostos da pedagogia Histórico-Crítica.

Para justificar a escolha do tema, precisamos compreender brevemente uma recapitulação histórica da EF escolar, e os desafios que permeiam a atuação do professor junto aos alunos e aos outros agentes envolvidos na comunidade escolar. Cabe ressaltar que, como professor de EF na rede do Rio, encontro diariamente uma série de questões que permeiam a minha prática, tanto entre os outros docentes, quanto com os alunos e seus responsáveis. Existe no imaginário social, uma impressão de que a EF (ainda nos dias de hoje), trata-se de um componente curricular descolado dos outros componentes, ou ainda uma disciplina pautada única e exclusivamente pelo gesto motor e na prática 
pela prática. Todavia, faz-se necessário delimitar novos caminhos de ressignificação para as práticas corporais na escola. Como esse movimento começa?

No final da década de 1970, emerge no país um processo de mobilização social em defesa da democratização da sociedade brasileira que promove um repensar da educação como processo de formação humana. A EF não se isola deste contexto e um segmento de intelectuais vinculados à área (a maioria deles com formação em nível de pós-graduação no campo das ciências humanas) passa a problematizar qual seria o objeto de estudo da área e explicitar os problemas existentes entre as concepções de EF. Esse processo desencadeou inúmeros debate/embates que deram origem a uma crise de identidade e de legitimidade que culminou na grande questão dessa década: o que é a EF?

Na década de 1980, uma das respostas à pergunta levantada nos anos anteriores foi a compreensão da EF como uma prática pedagógica que ocorre no interior da escola. Emerge a partir dessa explicação a teorização da área de conhecimento e surgem diferentes propostas pedagógicas para tratar pedagogicamente os conteúdos da disciplina. Tais propostas se consolidaram durante os anos 1990, ora convergindo, ora divergindo em relação à função da EF e a metodologia a ser utilizada. A entrada no século XXI, desde a consolidação dessas perspectivas pedagógicas, traz como desafio pensar sobre como tematizar os conteúdos da EF escolar, vinculados a uma determinada realidade escolar e a um projeto social.

Betti, Ferraz e Dantas (2011), ao analisar 289 artigos caracterizados como pesquisa em EF escolar, publicados em 11 periódicos (revistas) brasileiras, indicam que predominam os estudos no ensino fundamental, nas práticas "jogo" e "esporte", e pesquisas de cunho descritivo-interpretativo das aulas de EF em várias dimensões e interrelações. Assim, os autores apontam a necessidade de maior direcionamento para as pesquisas nos âmbitos da didática, para a contribuição de uma maior discussão acerca do trato pedagógico dos conteúdos.

Buscando operacionalizar essa pesquisa, a escolha do método deve permitir o diálogo a partir de um olhar único do sujeito que se relaciona com o seu objeto de estudo e, ainda como afirma Goldenberg (2007, p.14), “o que determina como trabalhar é o problema que se quer trabalhar: só se escolhe o caminho quando se sabe aonde se quer chegar". Dessa maneira, esse trabalho consiste em uma abordagem qualitativa, onde foi relatada a experiência do trato pedagógico do futebol, dentro das teorias críticas da 
Educação e da EF. Essa análise partiu do referencial teórico e da influência da pedagogia Histórico-Crítica e dos elementos da cultura corporal no planejamento, sistematização dos conteúdos e prática pedagógica durante as intervenções junto a turma de $6^{\circ}$ ano de uma escola municipal do Rio.

Durante o segundo bimestre no ano de 2018, o tema "Futebol: da Antiguidade à Copa do Mundo na Rússia - 2018”, contou com o planejamento e a sistematização das aulas. O planejamento para o $6^{\circ}$ ano teve como tema: a) Evolução histórica; b) Evolução das regras do futebol; c) As variações do futebol: futebol para cegos, totó-humano, futebol de cabeça, futsal, futevôlei e o futebol americano; d) Os jogos e brincadeiras de rua derivados do futebol: o gol a gol, a linha, e o "bobinho". E, por fim, além desses temas, acrescentou-se: "Júri escolar: o Brasil e as Copas do Mundo" e "Criando um jogo novo". As aulas foram realizadas em três tempos semanais, de 50 minutos cada. A unidade escolar em questão, possui uma quadra poliesportiva coberta, além de um pátio para a realização das atividades. Em relação aos materiais utilizados nas aulas, são em sua maioria adquiridos pelo professor, visto que a escola não dispõe de muitos recursos.

Segundo o Coletivo de Autores (1992, p.76), o trato com os conteúdos para a aula e seus temas deve partir de critérios de seleção, organização, transmissão e avaliação de conteúdos e metodologias do ensino, buscando referenciá-los nos interesses individuais e coletivos, no projeto pedagógico e no processo histórico. Esse processo foi inerente ao planejamento das aulas e das intervenções acerca do conteúdo futebol, na experiência aqui relatada.

\section{DESENVOLVIMENTO}

O consenso em torno da legitimidade da instituição escolar na sociedade contemporânea é um dado consolidado. Entretanto, um problema persiste: tais formulações restringem a formação humana e, consequentemente, limitam a possibilidade de inserção no mundo real. Diante disso, cabe uma questão: a educação escolar pode oferecer outra perspectiva formativa que supere o "economicismo" da teoria do capital humano e a orientação política da educação para a cidadania? Qual o papel do conhecimento sistematizado nesta alternativa pedagógica?

Buscando responder essa questão que alguns educadores brasileiros procuraram delinear uma possibilidade pedagógica sobre a especificidade e função da educação 
escolar, tendo em vista a necessidade de elevar a escolaridade das crianças e adolescentes da classe trabalhadora. Dermeval Saviani, no início da década de 1980, sistematiza e analisa criticamente, formulando sua concepção pedagógica a partir da dinâmica da sociedade capitalista. Conhecendo os limites desta forma cultural de organização da vida, o segundo passo foi analisar as concepções pedagógicas existentes, considerando as necessidades da classe trabalhadora e os objetivos da classe burguesa. A primeira constatação foi que os processos de dominação e exploração típicos das formações sociais capitalistas impedem a emancipação humana. A segunda constatação foi que as concepções pedagógicas existentes eram expressões específicas do projeto de sociedade da classe dominante.

Levando em consideração à questão da marginalidade, Saviani aponta que as teorias educacionais podem ser classificadas em dois grupos e ressalta que ambos tentam explicar a marginalidade fazendo um paralelo entre educação e sociedade. O primeiro grupo, denominado por Saviani de "Teorias não-críticas", composto pela Pedagogia Tradicional, a Pedagogia Nova (“aprender a aprender”) e a Pedagogia Tecnicista entendem a educação como instrumento de equalização social, portanto, de superação da marginalidade. Já o segundo grupo, nomeado de "Teorias Crítico-Reprodutivistas" que abarca a Teoria do Sistema de Ensino como Violência Simbólica, a Teoria da Escola como Aparelho Ideológico do Estado e a Teoria da escola Dualista, compreendem a educação como instrumento de discriminação social, ou seja, fator de marginalização. $\mathrm{O}$ autor considera o segundo grupo como teorias críticas, pois estas buscam entender a educação "[...] remetendo-a sempre a seus condicionantes objetivos" (SAVIANI, 2012, p.05), quer seja, à estrutura socioeconômica que determina a forma de manifestação do fenômeno educativo.

Duarte (2012) defende que os embates com o construtivismo e outras pedagogias do aprender a aprender, necessitam de lutas árduas por várias razões. A força dessas pedagogias vem do fato que elas se encaixam perfeitamente no ambiente da escola capitalista contemporânea. Daí vem sua força de atração. Além disso, elas têm uma grande capacidade de modificação de seus nomes, e de seu vocabulário e estratégias discursivas e práticas, ou seja, possuem um elevado grau de mutabilidade. Mas há um ponto que une todas elas e que não se altera: a guerra permanente à socialização da escola pública (DUARTE, 2012, p.156-157). 
Saviani discute em cada uma das teorias anteriormente citadas a questão da marginalidade. Para as teorias não-críticas, a marginalidade é considerada um desvio e a educação tem como função corrigi-lo. Já para o grupo das teorias crítico-reprodutivistas a marginalidade é um problema social e a educação, que dispõe de autonomia em relação à sociedade, estaria capacitada a intervir eficazmente na sociedade, transformando-a e promovendo assim a equalização social. $\mathrm{O}$ autor destaca que "[...] enquanto as teorias não-críticas pretendem ingenuamente resolver o problema da marginalidade por meio da escola, sem jamais conseguir êxito, as teorias crítico-reprodutivistas explicam a razão do suposto fracasso" (SAVIANI, 2012, p.24).

Após apresentar o diagnóstico das principais teorias pedagógicas ressaltando as contribuições e limites de cada uma, Saviani anuncia que a tarefa de uma teoria crítica que não seja reprodutivista é superar tanto o poder ilusório, característico das teorias nãocríticas, como a impotência, presente nas teorias crítico-reprodutivistas, “[...] colocando nas mãos dos educadores uma arma de luta capaz de permitir-lhes o exercício de um poder real, ainda que limitado" (SAVIANI, 2003, p.25).

A síntese dessa análise pode ser assim descrita: é necessário superar as teorias e experiências existentes fornecendo aos educadores uma concepção de educação que esteja vinculada ao compromisso com a emancipação da classe trabalhadora (SAVIANI, 2003). O resultado dessa sistematização foi denominada, Pedagogia Histórico-Crítica. Sua fundamentação encontra-se alicerçada no materialismo histórico.

O ponto de partida desta concepção foi compreender a condição humana e a função da educação na vida social. Sobre o primeiro aspecto, recuperando as ideias de Friedrich Engels e Karl Marx, a Pedagogia Histórico-Crítica afirma que os seres humanos precisam criar permanentemente as condições de sua existência. Enquanto os outros animais se adaptam ao mundo natural, coletivamente, os seres humanos transformam este mesmo mundo para viabilizar a existência da vida, produzindo cultura. Em outras palavras, não encontramos tudo de que precisamos pronto, somos obrigados a produzir formas materiais e não materiais, necessárias à vida - formas que nascem da necessidade objetiva (alimentação, por exemplo) e dos desejos e fantasias - e a transmitir estas formas para outras gerações.

Os seres humanos criam estas condições por meio de uma capacidade que desenvolveram ao longo da história: a capacidade de antecipar o plano do pensamento e 
traduzir esta antecipação em ações concretas e intencionais para viabilizar a vida - algo que Engels e Marx denominaram de trabalho. Por meio do trabalho - uma forma bem mais elaborada que a ação instintiva dos demais animais para suprir as necessidades e vontades que os seres humanos possuem - os seres humanos ultrapassam a determinação biológica para assumir a condição mais complexa: ser cultural. Por cultura compreendese a forma de organização e produção da vida que envolve a política, a economia, as artes, os hábitos e costumes predominantes em uma formação social e tempo histórico (CHAUÍ, 1995).

Com base nesta concepção, a função da educação para a Pedagogia HistóricoCrítica se vincula à produção da existência humana, portanto a condição de cultura. Enquanto predominou na criação e organização das condições de existência processos mais simples de trabalho, foi possível educar os mais novos no próprio processo de trabalho. Na medida em que as condições humanas se tornaram mais complexas, além dos processos informais, foi requerida a institucionalização da educação na forma escolar, que foi criada para oferecer as bases para a produção coletiva da existência humana.

No meu momento atual entendo a educação enquanto processo, tal como afirma Saviani (2012, p.17):

Podemos, pois, dizer que a natureza humana não é dada ao homem, mas é por ele produzida sobre a base da natureza biofísica. Consequentemente, o trabalho educativo é o ato de produzir, direta e intencionalmente, em cada individuo singular, a humanidade que e produzida histórica e coletivamente pelo conjunto dos homens. Assim, o objeto da educação diz respeito, de um lado, a identificação dos elementos culturais que precisam ser assimilados pelos indivíduos da espécie humana para que eles se tornem humanos e, de outro lado e concomitantemente, a descoberta das formas mais adequadas para atingir esse objetivo.

Portanto a formação humana pode/deve ter no seu horizonte a perspectiva de humanização. É esta formação humana que desenvolverá e potencializará o desenvolvimento das capacidades do homem (Dutra e Moraes, s/d, p.05). Contudo, cabe ressaltar que a produção da existência humana se faz por meio de relações sociais. Essas relações assumem formas específicas, envolvendo a denominação e exploração políticoeconômica de grupos sociais sobre outros grupos sociais. Significa afirmar que a relação entre trabalho e educação foi sendo delineada a partir do conteúdo e da forma como as relações sociais se desenvolvem na sociedade de classes. 
O projeto dominante defende que a classe trabalhadora deve ser mantida na condição de subalternidade sócio-político-econômica. A orientação é para que as crianças e adolescentes desta classe sejam educados para se tornarem um "recurso humano" para o desenvolvimento econômico capitalista e para obedecer às "regras sociais" para a harmonia social desta sociedade contraditória.

Reconhecendo que os seres humanos podem viver em outras condições e verificando que o projeto dominante encontra resistência na dinâmica escolar, a Pedagogia Histórico-Crítica procura oferecer aos educadores críticos uma teoria educacional alternativa de caráter contra-hegemônico. A perspectiva é afirmar que os alunos da classe trabalhadora precisam ser educados para assumirem as condições objetivas necessárias à direção do processo histórico, tem em vista a emancipação humana.

A perspectiva é que os alunos: $\left(1^{\circ}\right)$ compreendam criticamente a organização e dinâmica das formas de produção da existência humana, especialmente a forma capitalista; $\left(2^{\circ}\right)$ dominem os conhecimentos sistematizados e as formas culturais existentes, compreendendo-os como produto e instrumento necessário à produção da existência; $\left(3^{\circ}\right)$ desenvolva a lógica dialética de organização do pensamento para superar a lógica formal e a passividade intelectual em busca da autonomia do pensar (SAVIANI, 2012).

Para a Pedagogia Histórico-Crítica é fundamental que os alunos não só assimilem conhecimentos, mas que construam sentidos e significados sobre a relação entre conhecimento-trabalho-vida no mundo real, complexo e contraditório. Os conteúdos das disciplinas que compõe o currículo escolar, ao invés de orientar para a abstração do pensamento ou ordenar a racionalidade técnica para o simples fazer, podem estabelecer mediações importantes para ampliar a compreensão sobre as dimensões da produção da existência humana. Trata-se de reestabelecer o nexo orgânico entre vida/trabalho e educação.

Nessa linha, o ensino e a aprendizagem do conhecimento sistematizado envolverá a compreensão da realidade vivida a partir do diálogo com os conhecimentos espontâneos e aqueles advindos da experiência. Não se trata de negar o conhecimento espontâneo e o conhecimento gerado pela experiência. Ao contrário, para a Pedagogia Histórico-Crítica é fundamental oferecer novas possibilidades de interpretação desses novos 
conhecimentos e seus significados para a vida humana. O que se busca então é ultrapassar o senso comum, a superficialidade e a abstração para assegurar que a apropriação do conhecimento sistematizado permita compreender e atuar nos processos de produção da existência humana e das relações de poder neles envolvidas. Nesta concepção, os conteúdos escolares ao invés de frios e vazios, como são típicos da pedagogia tradicional e tecnicista, produzem sentidos e significados para o professor e o aluno porque se vinculam de forma mais ou menos indireta aos processos reais de produção material e simbólica dos meios necessários à vida e à interpretação das relações de poder envolvidas nestes processos.

Enquanto sujeitos do processo educativo, professores e alunos partem juntos da prática social, isto é, da realidade vivida pela humanidade para compreender o mundo real, interpretar as formas de produção deste mundo e estabelecer possibilidades para agir nele. É claro que, enquanto espaço social, a escola se materializa enquanto instância de sociabilidade, onde há encontros humanos ricos e profundos para a experiência de crianças e adolescentes. Entretanto, o que justifica a especificidade da instituição escolar não é o simples convívio, ainda que ele seja importante, mas sim a necessidade de apropriação coletiva do conhecimento sistematizado, tendo em vista a compreensão da condição humana e as possibilidades de intervenção no mundo.

Reconhecer a especificidade da educação escolar é importante para que as práticas pedagógicas não sejam orientadas para rebaixar a escolarização destinada aos filhos da classe trabalhadora. Enquanto espaço de vivência coletiva, a instituição escolar deve ter claro que função deve cumprir na sociedade. Esvaziar o currículo escolar de conhecimento sistematizado e valorizar os saberes advindos da experiência imediata como centro do processo educativo é um meio que vem sendo usado para comprometer a formação das crianças e adolescentes da classe trabalhadora, mantendo-os na condição de subalternidade.

O desafio proposto pela Pedagogia Histórico-Crítica é tornar a instituição escolar um espaço que socializa os conhecimentos sistematizados para permitir o domínio para os meios necessários à inserção ativa na vida social, com horizonte da emancipação humana. É possibilitar que os processos pedagógicos escolares assegurem a todos, indistintamente, aquilo que se tornou indispensável para compreender/agir o/no mundo: o conhecimento científico, filosófico e artístico. 
Vivemos numa sociedade de classes. Sob esta condição, pensar a função e especificidade da educação escolar é tratar dos projetos formativos que disputam a formação humana nesta sociedade. É também considerar a posição das perspectivas pedagógicas em relação ao tratamento dispensado ao conhecimento sistematizado. É compreender que as definições pedagógicas não são simples escolhas técnicas arbitrárias.

Isso revela que o trabalho educativo, entendido como " $[\ldots]$ o ato de produzir, direta e intencionalmente, em cada indivíduo singular, a humanidade que é produzida histórica e coletivamente pelo conjunto dos homens" (SAVIANI, 2012, p. 13), na sociedade de classes é algo muito complexo que exige do professor rigor na tomada de posições, compromisso político com um projeto de sociedade que assume o domínio dos instrumentos pedagógicos para transformar a intenção educativa em algo real na formação humana. As possibilidades teóricas existem e elas se vinculam aos interesses de classe.

Para a Pedagogia Histórico-Crítica é preciso educar para contribuir com o desafiador e difícil processo de valorização da vida humana, e não das coisas, e construção da emancipação. Sua perspectiva é oferecer aos educadores do campo crítico uma alternativa teórica e metodológica para a construção da mudança, valorizando a instituição escolar em um espaço rico e dinâmico de ensino-aprendizagem repleto de sentidos e significados para os que precisam romper com a dominação e a exploração de classes.

No que tange o objeto de conhecimento que deve ser apropriado pelo aluno, dentro de um currículo escolar, temos a EF e seus conteúdos. Nesse estudo adotamos como referencial teórico o Coletivo de Autores (1992), que tem como fundamento, também, o materialismo histórico-dialético, no qual a concepção crítico-superadora considera como objeto de estudo a cultura corporal (que são as manifestações construídas historicamente e que será configurada como temas: o jogo, os esportes, a dança, a ginástica, as lutas, o contorcionismo etc.), que foi historicamente construída pela humanidade de acordo com as suas necessidades, até os dias atuais.

Ao defender uma perspectiva de reflexão da cultura corporal, o Coletivo de Autores (1992) justifica que a expressão corporal é uma linguagem, um conhecimento universal, patrimônio da humanidade que igualmente precisa ser transmitido e assimilado pelos alunos na escola. Assim sendo, a reflexão sobre a cultura corporal possibilita a compreensão da realidade natural e social, complexa e contraditória, em uma visão de 
totalidade. Desse modo, a concepção crítico-superadora propõe que o trato com o conhecimento se dê de forma diferenciada do que vem ocorrendo, defendendo uma concepção de currículo ampliado, que diz respeito a uma formação que considera a relação entre as matérias enquanto partes e o currículo enquanto todo é uma das referências do conceito de currículo ampliado que propõe.

Para a efetivação de um currículo ampliado, o processo de planejamento é fundamental para a ação pedagógica, mas não se resume a isso. É fundamental que o professor atue efetivamente como um mediador no que diz respeito à definição e direção da aula. O professor deve perceber o aluno na sua totalidade, assim será possível superar a ideia de que ação educativa dos professores de Educação Física se dirige somente à dimensão motora, ou melhor, a uma formação corporal desvinculada de outras dimensões que compõem a totalidade do ser humano, superando uma visão fragmentária de homem desvinculada dos determinantes políticos, econômicos e culturais. Quem decide em favor da vida tem de "mergulhar" nela em sua totalidade. E quem decide mergulhar não pode esperar molhar apenas uma parte de seu corpo. Quem mergulha molha-se "inteiro". Ou se acredita no homem ou não se acredita (MEDINA, 1990, p.29).

A partir da reflexão referente ao sentido que habilita a EF como disciplina no currículo escolar, levamos em conta como esse conhecimento foi desenvolvido e qual o seu papel enquanto elemento construtivo e atuante na realidade social dos alunos. Isso quer dizer que se deve explicar ao aluno que a produção humana, seja intelectual, científica, ética, moral, afetiva etc., expressa um determinado estágio da humanidade e que não foi assim em outros momentos históricos (COLETIVO DE AUTORES, 1992, p.33), preservando um aspecto importante do aluno que é a singularidade. Por meio dessa organização pretende-se formar um cidadão crítico e consciente da realidade social em que vive, com poder de nela intervir.

De acordo com HURTADO (2003):

A EF se justifica na escola já que não há outra prática pedagógica que
se ocupe da dimensão cultural de que só a Educação Física trata que é
a cultura de movimento humano, expressa nos jogos, nas danças, nas
lutas, nos esportes e nas ginásticas. Se o objetivo da escola é atender à
educação global do aluno, deixar de lado este aspecto de nossa cultura,
parte do patrimônio cultural da humanidade, que está tão presente em
nosso dia-a-dia, é algo impensável. Temos que dar nossa contribuição
para que nosso aluno possa conhecer, escolher, vivenciar, transformar,
planejar e ser capaz de julgar os valores associados à prática da 
atividade física, mais do que apenas praticar sem entender essa prática, simplesmente aderindo (ou não) à moda da atividade física. (p.40)

Ao delimitar os conteúdos da EF escolar, deve-se estar atento aos princípios da lógica dialética como totalidade, movimento e contradição deverão ser norteadores da prática pedagógica e da escola que pretende superar o conservadorismo. A seleção dos conteúdos deverá ter como ponto de partida os elementos da cultura corporal, levando em conta a realidade social concreta, bem como os determinantes históricos, assim como os dados da conjuntura nacional e internacional. Deverá também seguir determinados princípios, tais como: a relevância social, que implica compreender o sentido e o significado do mesmo para a reflexão pedagógica escolar.

De acordo com o Coletivo de Autores (1992, p.40):

A expectativa da Educação Física escolar tem como objetivo a reflexão sobre a cultura corporal, contribui para a afirmação dos interesses de classes das camadas populares, na medida em que se desenvolve uma reflexão pedagógica sobre os valores como solidariedade substituindo individualismo, cooperação confrontando a disputa, distribuição em confronto com apropriação, sobretudo enfatizando a liberdade de expressão dos movimentos - a emancipação - negando a dominação e submissão do homem pelo homem.

Para esses autores, este deverá estar vinculado à explicação da realidade social concreta e oferecer subsídios para a compreensão dos determinantes sócio-históricos do aluno, particularmente a sua condição de classe social. A contemporaneidade, que significa garantir aos alunos o que de mais moderno existe no mundo contemporâneo, mantendo-o informado dos acontecimentos nacionais e internacionais, bem como do avanço da ciência e da técnica, a adequação às possibilidades sócio-cognitivas do aluno, que se refere, no momento da seleção, competência para adequar o conteúdo à capacidade cognitiva e à prática social do aluno, ao seu próprio conhecimento e às suas possibilidades enquanto sujeito histórico.

A simultaneidade dos conteúdos enquanto dados da realidade. A partir desse princípio, os conteúdos de ensino são organizados e apresentados aos alunos de maneira simultânea. A espiralidade da incorporação das referências do pensamento, que significa compreender as diferentes formas de organizar as referências do pensamento sobre o conhecimento para ampliá-las, além da provisoriedade do conhecimento, onde com base nele, organizam-se e sistematizam-se os conteúdos de ensino, rompendo com a ideia de terminalidade. 
Através desses aspectos norteadores acerca da delimitação dos conteúdos, a EF escolar tem a oportunidade de reconhecer sua importância e relevância social. Afinal, agregando objetivos gerais e específicos será possível realizar através da educação a transformação social que permitirá a construção de uma sociedade mais igualitária, onde não exista a reprodução do "movimento pelo movimento". Assim sendo, cabe à EF auxiliar através de seus conteúdos historicamente construídos, a formação desses cidadãos.

Para formar esse tipo de sujeito, o paradigma da reflexão crítica sobre a cultura corporal defende a tematização dos conteúdos de forma crítico-superadora. A tematização defendida por esta proposta abrange a compreensão das relações de interdependência que os diferentes conteúdos da cultura corporal têm com os grandes problemas sócio-políticos atuais, como "[...] ecologia, papéis sexuais, saúde pública, relações de trabalho, preconceitos sociais, raciais, da deficiência, da velhice, distribuição do solo urbano, distribuição de renda, dívida externa e outros" (COLETIVO DE AUTORES, 1992, p.623). Assim, busca-se desenvolver uma reflexão pedagógica sobre as formas de representação do mundo exteriorizadas pela expressão corporal que o ser humano tem produzido no decorrer da história, dentre as quais pode-se destacar: jogos, danças, lutas, exercícios ginásticos, esportes, malabarismos, contorcionismos, mímica e outros, que podem ser identificados como formas de representação simbólica de realidades vividas pelo homem, historicamente criadas e culturalmente desenvolvidas (COLETIVO DE AUTORES, 1992).

Portanto, pode-se afirmar que a metodologia crítico-superadora, ao alinhar-se à perspectiva pedagógica defendida por Dermeval Saviani, busca propor novos caminhos para a apropriação do conhecimento na escola, inclusive pela organização metodológica fundamentada nos cinco passos do método dialético de transmissão do conhecimento, a saber: identificação da prática social, problematização, instrumentalização, catarse e retorno à prática social.

O ponto de partida para a apropriação do conhecimento é a prática social (SAVIANI, 2003). Nesse passo, conforme apresentado por Gasparin (2005), realiza-se um primeiro contato com o tema a ser estudado par evidenciar suas relações com a vida cotidiana, visando mobilizar os alunos para o processo pedagógico. Segundo este autor, a identificação da prática social pode ser dividida em duas partes, a saber: anúncio e 
vivência cotidiana dos conteúdos. No anúncio dos conteúdos aponta-se o que será estudado e quais os objetivos a serem alcançados. Na vivência cotidiana dos conteúdos, identifica-se o que os alunos já sabem e o que eles gostariam de saber mais sobre o assunto em questão.

O segundo passo do método dialético de construção do conhecimento escolar é a problematização, fase na qual se busca “[...] detectar que questões precisam ser resolvidas no âmbito da prática social e, em consequência, que conhecimento é necessário dominar" (SAVIANI, 2003, p.71). A partir dessa afirmação, dois aspectos importantes foram salientados por Gasparin (2005), que merecem um devido destaque.

$\mathrm{O}$ primeiro deles diz respeito às questões da prática social que devem ser detectadas. O autor esclarece, com base no próprio Saviani, que o foco deve ser concentrado nas grandes questões que desafiam a sociedade, nos principais problemas que precisam ser resolvidos não só na escola, ou pela escola, mas no âmbito da sociedade. Para isso, afirma que deve ser feita uma seleção do que é fundamental, visto que os principais problemas postos pela prática social nem sempre podem ser tratados na sua totalidade em cada área do conhecimento. O "fundamental", vale dizer, refere-se aos aspectos relacionados ao conteúdo estabelecido pelo currículo escolar ou aos conhecimentos trabalhados em uma determinada unidade do programa. Com base nesse entendimento, pode-se dizer que a problematização deve selecionar e discutir os problemas que tem origem na prática social, mas que ao mesmo tempo, ligam-se ao conteúdo a ser trabalhado: trata-se de uma seleção e discussões de grandes questões sociais, porém, inseridas e especificadas no conteúdo da unidade que está sendo estudada (GASPARIN, 2005).

O segundo aspecto a ser destacado refere-se a qual conhecimento é necessário dominar para resolver os problemas da prática social. Gasparin (2005) explica que, de maneira geral, os conteúdos são, quase sempre, transmitidos aos educandos por uma única dimensão: a conceitual-científica. Em virtude da ênfase geralmente atribuída a essa dimensão do conteúdo, o autor alerta o seguinte: é necessário lembrar, no processo de construção de conhecimento, que a ciência também é um produto social, originada de necessidades históricas, econômicas, políticas, ideológicas, filosóficas, religiosas, técnicas, entre outras. Tendo em vista o fato de que existem outras dimensões que revestem os diferentes conteúdos, faz-se necessário abordar, na construção do 
conhecimento, não só a dimensão conceitual-científica. A necessidade de transcender a abordagem centrada na dimensão conceitual provém do entendimento de que a análise do real deve considerar suas múltiplas dimensões visto que a realidade social envolve sempre uma gama de perspectivas, um conjunto de aspectos interdependentes, que devem ser entendidos para a resolução dos problemas postos pela prática social. É importante destacar esse aspecto sobretudo porque, na Educação Física, a ênfase do processo pedagógico geralmente é concentrada nos elementos técnicos e táticos, o que desconsidera as múltiplas dimensões que revestem o conteúdo em questão.

Assim, duas tarefas principais podem ser operacionalizadas na problematização. A primeira delas envolve o questionamento da prática social e do conteúdo escolar. Tratase de um momento em que são apresentadas e discutidas as razões sociais pelas quais se deve aprender o conteúdo proposto, de modo que os alunos possam entender melhor o que será estudado, identificar os principais problemas postos pela prática social e pelos conteúdos e, ainda, entender a necessidade e/ou entender melhor os problemas da prática social (GASPARIN, 2005). A segunda tarefa que pode ser realizada na problematização refere-se às dimensões do conteúdo a serem trabalhadas. Em linhas gerais, pode-se dizer que essa tarefa consiste em definir as dimensões que se deseja estudar. Para tanto, podese partir do conteúdo a ser trabalhado, de modo a elaborar questões desafiadoras que expressem dimensões específicas referentes à natureza do conteúdo, como por exemplo, as dimensões científico-conceituais, sociais, econômicas, culturais, históricas, filosóficas, morais, éticas, estéticas, legais e doutrinárias (GASPARIN, 2005).

O passo seguinte, a instrumentalização, segundo Gasparin (2005), é o caminho através o do qual o conteúdo sistematizado é posto à disposição dos alunos para que assimilem, o recriem e, ao incorporá-lo, transformem-no em instrumento cultural para transformação da realidade. Esse terceiro passo do método dialético de transmissão do conhecimento consiste no momento em que os alunos vão se apropriar das ferramentas culturais necessárias à luta social que travam diariamente para se libertar das condições de opressão em que vivem; ou seja, trata-se da fase na qual ocorre a apropriação dos instrumentos teóricos e práticos necessários ao equacionamento dos problemas detectados na prática social (SAVIANI, 2006).

De acordo com Saviani (2006), o quarto passo do método é a “catarse", momento de expressão elaborada da nova forma de entendimento da prática social a que se 
ascendeu. "Trata-se da efetiva incorporação dos instrumentos culturais, transformados agora em elementos ativos da transformação social" (SAVIANI, 2003, p. 72). Pode-se dizer que a catarse é a demonstração teórica do ponto de chegada, do nível superior atingido pelos alunos (GASPARIN, 2005).

Por fim, retorno à prática social, temos a nova maneira de compreender a realidade e posicionar-se diante dela: é a manifestação da nova postura prática, da nova atitude, da nova visão do conteúdo no cotidiano. Trata-se, de acordo com Gasparin (2005), do momento de ação consciente em prol da transformação da realidade, a partir do retorno à prática social, agora entendida de forma mais elaborada.

Levando em conta esses diferentes momentos do método dialético de construção do conhecimento, o ensino dos diferentes conteúdos que compõe a cultura corporal permite aos alunos se apropriem dos conhecimentos acumulados historicamente pela humanidade. Trata-se de um importante passo no sentido de enriquecer a concepção de mundo dos alunos, uma vez que o acesso ao saber sistematizado sobre jogos, esporte, luta, dança, ginástica, circo, por exemplo, se constitui como elemento indispensável para a leitura dessa dimensão da realidade. Especificamente, nesta pesquisa, abordaremos o desenvolvimento das aulas acerca do futebol e suas representações dentro da cultura corporal.

\section{RESULTADOS E DISCUSSÃO}

Através da sistematização das aulas, partindo das recomendações preconizadas pela metodologia crítico-superadora da EF, proposta pelo Coletivo de Autores (1992), relacionamos a contemporaneidade, visto que foram realizados simultaneamente à Copa do Mundo da Rússia, tendo em vista sua relevância social, expressa pela mídia e pelos meios de comunicação. O tema "Futebol: da Antiguidade à Copa do Mundo na Rússia", contou com o planejamento e a sistematização das aulas. O planejamento teve como tema: a) Evolução histórica; b) Evolução das regras do futebol; c) As variações do futebol: futebol para cegos, totó-humano, futevôlei e o futebol americano; d) Os jogos e brincadeiras de rua derivados do futebol: o gol a gol, a linha e o "bobinho".

A partir da contextualização do conteúdo e da preocupação com o trato pedagógico dado ao futebol, podemos citar como elementos em nossa prática pedagógica: a relevância social do futebol em nossa sociedade, a provisoriedade do conhecimento 
dada a historicidade dos fatos e o processo de institucionalização do futebol. Através da evolução das regras e da criação de novas, consideramos como momento relevante entre tantos outros, aquele onde os alunos vivenciaram a oportunidade de participar da aula ativamente, oferecendo suas ideias e decidindo coletivamente, como no caso do "Júri escolar", onde os alunos protagonizaram um tribunal e deveriam defender os prós e contras acerca da seguinte questão: “o Brasil é o país do futebol? ”

A adequação às possibilidades cognoscitivas dos alunos, onde adaptamos as atividades de acordo com as possibilidades apresentadas pela turma. Podemos assim relacionar, outros dois princípios que são os da espiralidade e a simultaneidade dos dados da realidade, onde apresentávamos os conteúdos de forma contínua e integrada, nunca fragmentada. Respeitar esses princípios é reconhecer as individualidades e possibilidades dos alunos mediante ao conhecimento. Por fim, procuramos trabalhar a provisoriedade do conhecimento na evolução histórica do futebol, onde os alunos puderam perceber que as regras oficiais, o sistema de jogo e suas ressignificações são heranças históricas construídas pela humanidade.

Partindo da prática social dos alunos, as problematizações, bem como a instrumentalização ao longo do projeto, permitiram, em vários momentos, que as discussões em sala de aula promovessem realmente a reflexão. Partimos para o planejamento participativo e, para nossa surpresa, antigos hábitos, como o de querer apenas jogar futebol, mostraram-se superados por novos conteúdos e novas experiências. Nas avaliações, os alunos demonstraram terem apreendido grande parte do que trabalhamos, partindo, na maioria das vezes, de uma prática social sincrética para uma prática social sintética, ou seja, contribuindo de forma mais efetiva para as aulas, aumentando em alguns casos sua participação.

Especificamente, no caso do futebol, decidimos realizar sua mediação, com base na sistematização da Pedagogia Histórico-Crítica. Primeiramente, dada sua relevância social e seu apelo diante dos alunos. Segundo, pelo fato de ser o conteúdo preferido da maioria dos alunos, há uma resistência por parte dos mesmos, de que as aulas não sejam mais do que "rolar a bola". O desafio é trabalhar o conteúdo futebol em todas as suas dimensões.

O primeiro contato dos alunos com o conteúdo a ser trabalhado na unidade didática em questão ocorreu na identificação da prática social, onde apontamos o assunto 
que foi desenvolvido durante as aulas. Também buscamos apreender o conhecimento inicial dos discentes, bem como as questões que tinham interesse em ampliar o saber. Apresentamos o conteúdo Futebol, delimitando o seguinte questionamento que direcionou nossas aulas: O futebol praticado na rua, ou na escola é o mesmo da Copa do Mundo? Em seguida, os alunos procuraram responder a partir de um debate preliminar, onde cada um deveria dar sua opinião sobre essas questões a fim de captarmos os saberes construídos pela vivência cotidiana dos alunos. Espera-se com isso, que os alunos manifestem o conhecimento que possuem sobre a temática, estabelecendo ou não uma relação entre o "futebol espetáculo" transmitido e veiculado pelos meios de comunicação, e o que praticam cotidianamente.

Após a breve discussão inicial, explicitamos os tópicos que seriam abordados durante o trabalho com o tema, a saber: o que você sabe sobre o futebol? A história do futebol; a evolução das regras; variações do futebol: os jogos tradicionais praticados na rua; o futebol em diferentes formas: futebol americano, futevôlei, e o futebol de índios; o "júri escolar”: “o Brasil é o país do futebol? ”; e, inventando um jogo novo. Em seguida, apresentamos os objetivos, as atividades a serem desenvolvidas, assim como a importância de se estudar esse tema.

A seleção de questões sociais que permeiam o conteúdo abordado, instigando o debate e a reflexão dos alunos, se expressa no segundo passo metodológico, a problematização. Nesta etapa, selecionaremos as dimensões do conteúdo que serão trabalhadas, estabelecendo os questionamentos relacionados à prática social, tal como sugere o plano de unidade apresentado a seguir.

$\mathrm{Na}$ instrumentalização, faze na qual ocorre, de fato, a apropriação do conhecimento sistematizado por parte do aluno, pretendíamos desenvolver atividades que contribuíssem para a elaboração de respostas aos questionamentos sistematizados anteriormente. As atividades docentes e discentes voltadas à transmissão/apropriação do conhecimento sistematizado envolveram a exposição do conteúdo pelos bolsistas e professor supervisor, análise de vídeos tratando sobre a história do futebol e a evolução da modalidade e suas regras, pesquisa sobre as variações do futebol praticadas cotidianamente, discussões sobre os espaços na cidade e na escola para a prática da modalidade, textos para o debate sobre os lados positivo e negativo no fato do Brasil ser chamado de "o Brasil é o país do futebol”, dentre outros. 
Para captar se os alunos se apropriaram do conhecimento elaborado que os capacita a responder questões presentes levantadas na problematização, pretendíamos aplicar duas atividades onde de forma coletiva, os alunos pudessem construir uma nova prática social a partir do que apreenderam em torno da questão inicial: $\mathrm{O}$ futebol praticado na rua, ou na escola é o mesmo da Copa do Mundo? Esperava-se que os alunos apontassem os principais impactos da promoção de eventos como a Copa do Mundo, o papel da mídia na veiculação das notícias desse acontecimento, e que se utilizassem dos elementos históricos e da evolução das regras e resgate dos jogos tradicionais de rua e das variações do futebol, para compreender a problemática - espaços na cidade e na escola, e características físicas e técnicas exigidas pelo alto-rendimento e performance - para a sua prática no ambiente escolar, e na cidade do Rio de Janeiro. Espera-se que os alunos superassem o entendimento predominante do senso comum, que diz "o Brasil será o campeão da Copa do Mundo, pois somos o país do futebol, como disse o Galvão Bueno" (resposta de vários alunos nas primeiras aulas); ou que "na televisão só passa futebol, e não passa tanto outros esportes" (reclamação de alguns alunos que não se interessam apenas pelo futebol); e ainda, que mulher não joga futebol porque não tem habilidade, ou força, etc.; ou a pergunta que a maioria dos professores de EF ouve ao entrar na sala: “professor(a), hoje vai ter futebol?” Será que o futebol é o único conteúdo nas aulas de EF, e com as possibilidades espaciais da escola, estamos praticando o futebol, ou são feitas variações da modalidade?

Dessa forma, promovemos o "Juri escolar", onde os alunos após a instrumentalização deveriam se organizar coletivamente e elaborar argumentos a favor e contra à expressão "o Brasil é o país do futebol”. Utilizamos como estratégia, o "Teatro do Oprimido ${ }^{3 "}$, que serviu para que os alunos dramatizassem a situação, tornando a aprendizagem prazerosa e significativa. E na aula seguinte, a aula girou em torno da atividade "criando um jogo novo", onde os alunos coletivamente teriam que criar um novo jogo, a partir dos elementos técnicos e organizacionais do jogo do futebol, no espaço escolar e com a participação de toda a turma. Durante as duas aulas, procuramos levantar

\footnotetext{
3 O "Teatro do Oprimido" (TO) é um método teatral que reúne exercícios, jogos e técnicas teatrais elaboradas pelo teatrólogo brasileiro Augusto Boal. Os seus principais objetivos são a democratização dos meios de produção teatral, o acesso das camadas sociais menos favorecidas e a transformação da realidade através do diálogo (tal como Paulo Freire pensou a educação) e do teatro.
} 
as diferentes abordagens do tema apresentadas pelos alunos, inclusive possibilitando a eles comparar as respostas produzidas nesse momento pedagógico, a catarse, com as respostas das primeiras aulas.

No retorno à prática social, pretendemos finalizar o trabalho pedagógico definido, juntamente com os alunos, novas intenções e propostas de ação - a partir da forma apresentada de compreender e lidar com o conteúdo/tema em questão. Interessante destacar, que nas aulas seguintes, já após o conteúdo "futebol", os alunos trouxeram algumas matérias sobre a monocultura do futebol na mídia e nos momentos de lazer, traçando posicionamento críticos sobre o assunto. Isso é um indicativo de uma nova prática social, capaz de fazer uma leitura de mundo diferente da antes explicitada, preocupada não apenas com a escalação da seleção para os jogos. Apresentaremos a seguir, o plano de ensino e sua sistematização do conteúdo futebol, dentro da Pedagogia Histórico-Crítica:

Plano de unidade: "O futebol: da antiguidade à Copa do Mundo na Rússia. " DISCIPLINA: Educação Física.

ANOS DE ESCOLARIDADE: $6^{\circ}$ ano do Ensino Fundamental. CONTEÚDO: Futebol/Esportes.

UNIDADE: O futebol praticado na rua, ou na escola é o mesmo da Copa do Mundo? NÚMERO DE AULAS: 12 aulas.

Objetivos: a) Compreender o futebol como uma manifestação social/cultural, criada em um determinado período histórico, e que evoluiu a partir de sua institucionalização, e a criação de suas regras; b) Resgatar e difundir jogos e brincadeiras tradicionais de rua, que envolvam variações do futebol, e reconhecer esses elementos em outras modalidades derivadas do futebol, ou que deram origem ao futebol, como o rúgbi, por exemplo; c) Refletir acerca dos espaços disponíveis na cidade e na escola para a prática do futebol; d) Promover o trabalho coletivo entre meninos e meninas, enaltecendo a possibilidade de atuarem juntos, independente de diferenças físicas ou técnicas, levando em consideração também o esporte praticado no alto rendimento; e) Analisar os diferentes discursos da mídia sobre a representatividade do futebol na cultura brasileira, para posicionar-se criticamente diante da problemática. 


\section{1) PRÁTICA SOCIAL INICIAL}

\subsection{Anúncio dos conteúdos:}

TÓPICOS:

- Futebol: Evolução histórica e regras gerais

- Variações do futebol

- Júri escolar: o Brasil e a Copa

- Criando o nosso próprio jogo

\subsection{Vivência cotidiana dos conteúdos:}

- O que os alunos já sabem sobre o conteúdo? O Brasil é o país do futebol, é o que falam na televisão; a aula de EF deveria ser só futebol; as meninas não sabem jogar, e por isso não gostam; os alunos jogam futebol na escola, na rua, e é possível jogar em qualquer lugar; o futebol se joga com os pés, e só o goleiro pode colocar a mão na bola.

- $\quad$ O que gostariam de saber mais? Onde surgiu o futebol? Como foram definidas suas regras?

\section{2) PROBLEMATIZAÇÃO}

\subsection{Discussão sobre o conteúdo:}

O que você sabe sobre o futebol? Qual sua origem? O que sabem sobre sua história, evolução e regras? Como vocês costumam praticar a modalidade fora dentro e fora da escola? O futebol jogado na escola é o mesmo que vemos na televisão? Qual evento esportivo está acontecendo na Rússia, neste ano?

\subsection{Dimensões do conteúdo a serem trabalhadas}

Tabela 1: Dimensões do conteúdo a serem trabalhadas

\begin{tabular}{|c|l|}
\hline DIMIENSÕES & \multicolumn{1}{|c|}{ QUESTÕES PROBLEMATIZADORAS } \\
\hline Conceitual & $\begin{array}{l}\text { O que é futebol? Quais suas principais regras? Por que o futebol } \\
\text { "futebol espetáculo"? }\end{array}$ \\
\hline
\end{tabular}




\begin{tabular}{|c|l|}
\hline Histórica & $\begin{array}{l}\text { Onde surgiu o futebol? Como suas regras foram sendo } \\
\text { construídas? Como o futebol chegou ao Brasil? O futebol que se } \\
\text { jogava na antiguidade se diferencia no que aos dias atuais? }\end{array}$ \\
\hline Social & $\begin{array}{l}\text { Qual o espaço na cidade onde se pratica o futebol? Como adaptar } \\
\text { o futebol para dentro da escola? Como é o jogo que vocês } \\
\text { costumam praticar com seus amigos? O Brasil é o país do futebol? }\end{array}$ \\
\hline Econômica & $\begin{array}{l}\text { Quais os impactos da realização da última Copa no Brasil? Quais } \\
\text { os pontos positivos e negativos? De onde virão os recursos para a } \\
\text { construção dos estádios? Estão investindo em infraestrutura? }\end{array}$ \\
\hline Política & $\begin{array}{l}\text { Por que o Brasil foi escolhido para sediar a Copa em 2014? O que } \\
\text { aconteceu com os estádios, após a realização da Copa? Como o } \\
\text { Brasil é visto pelos outros países, e como a Copa pode contribuir } \\
\text { para isso? }\end{array}$ \\
\hline Ética & $\begin{array}{l}\text { Só joga futebol quem sabe jogar? Como incluir toda a turma na } \\
\text { atividade, independente das individualidades? Quem não sabe } \\
\text { jogar, fica de fora? }\end{array}$ \\
\hline Cultural & $\begin{array}{l}\text { A maioria das meninas não sabe jogar por que não gosta, ou não } \\
\text { gosta por que não sabem jogar? O Brasil é o país do futebol? } \\
\text { Quais variações do futebol vocês conhecem? }\end{array}$ \\
\hline
\end{tabular}

Fonte: elaboração própria com base em Gasparin (2005)

\section{CENTES E DISCENTES E RECURSOS}

Tabela 2: Instrumentalização

\begin{tabular}{|c|c|c|c|c|}
\hline CONTEÚDO & OBJETIVOS & DIMIENSÕES & AÇÕES & RECURSOS \\
\hline $\begin{array}{c}\text { Evolução } \\
\text { histórica e } \\
\text { regras gerais }\end{array}$ & $\begin{array}{c}\text { Compreender o } \\
\text { futebol como } \\
\text { uma } \\
\text { manifestação } \\
\text { social/cultural, } \\
\text { criada em um } \\
\text { determinado } \\
\text { período } \\
\text { histórico, e que } \\
\text { evoluiu a partir } \\
\text { de sua } \\
\text { institucionalizaç } \\
\text { ão, e a criação } \\
\text { de suas regras. }\end{array}$ & $\begin{array}{l}\text { Conceitual } \\
\text { Histórica } \\
\text { Política } \\
\text { Econômica }\end{array}$ & $\begin{array}{c}\text { Pesquisa sobre a } \\
\text { história do } \\
\text { futebol, e suas } \\
\text { regras. } \\
\text { Vivência prática } \\
\text { da evolução do } \\
\text { jogo e das regras. }\end{array}$ & $\begin{array}{c}\text { Livros e } \\
\text { artigos da } \\
\text { imprensa } \\
\text { (jornais, } \\
\text { revistas e } \\
\text { internet); } \\
\text { slides e } \\
\text { vídeos } \\
\text { (computador } \\
\text { e data-show); } \\
\text { bolas. }\end{array}$ \\
\hline
\end{tabular}




\begin{tabular}{|c|c|c|c|c|}
\hline $\begin{array}{l}\text { Variações do } \\
\text { futebol }\end{array}$ & $\begin{array}{c}\text { Resgatar e } \\
\text { difundir jogos e } \\
\text { brincadeiras } \\
\text { tradicionais de } \\
\text { rua, que } \\
\text { envolvam } \\
\text { variações do } \\
\text { futebol, e } \\
\text { reconhecer esses } \\
\text { elementos em } \\
\text { outras } \\
\text { modalidades } \\
\text { derivadas do } \\
\text { futebol, ou que } \\
\text { deram origem ao } \\
\text { futebol, como o } \\
\text { rúgbi, por } \\
\text { exemplo; } \\
\text { Refletir acerca } \\
\text { dos espaços } \\
\text { disponíveis na } \\
\text { cidade e na } \\
\text { escola para a } \\
\text { prática do } \\
\text { futebol. }\end{array}$ & $\begin{array}{c}\text { Histórica } \\
\text { Cultural } \\
\text { Social }\end{array}$ & $\begin{array}{l}\text { Entrevista com } \\
\text { pessoas mais } \\
\text { velhas sobre os } \\
\text { jogos de sua } \\
\text { época. } \\
\text { Reconhecer os } \\
\text { espaços da escola } \\
\text { e da cidade, a } \\
\text { partir do } \\
\text { levantamento de } \\
\text { possíveis espaços } \\
\text { para a prática da } \\
\text { modalidade. } \\
\text { Vivência prática } \\
\text { das variações do } \\
\text { futebol. }\end{array}$ & $\begin{array}{c}\text { Bolas, cones, } \\
\text { cordas. }\end{array}$ \\
\hline $\begin{array}{l}\text { Júri escolar: o } \\
\text { Brasil e a Copa }\end{array}$ & $\begin{array}{c}\text { Analisar os } \\
\text { diferentes } \\
\text { discursos da } \\
\text { mídia sobre a } \\
\text { representatividad } \\
\text { e do futebol na } \\
\text { cultura } \\
\text { brasileira, para } \\
\text { posicionar-se } \\
\text { criticamente } \\
\text { diante da } \\
\text { problemática. }\end{array}$ & $\begin{array}{c}\text { Econômica } \\
\text { Política } \\
\text { Social } \\
\text { Cultural } \\
\text { Ética }\end{array}$ & $\begin{array}{l}\text { Leitura de textos } \\
\text { para o debate. } \\
\text { Dramatização } \\
\text { através do teatro } \\
\text { do oprimido. } \\
\text { Cada grupo teria } \\
\text { que sintetizar seus } \\
\text { argumentos de } \\
\text { forma teórica para } \\
\text { registro. }\end{array}$ & $\begin{array}{l}\text { Textos } \\
\text { retirados da } \\
\text { internet. }\end{array}$ \\
\hline $\begin{array}{c}\text { Criando o } \\
\text { nosso próprio } \\
\text { jogo }\end{array}$ & $\begin{array}{l}\text { Promover o } \\
\text { trabalho coletivo } \\
\text { entre meninos e } \\
\text { meninas, } \\
\text { enaltecendo a } \\
\text { possibilidade de } \\
\text { atuarem juntos, } \\
\text { independente de } \\
\text { diferenças } \\
\text { físicas ou } \\
\text { técnicas, levando }\end{array}$ & $\begin{array}{c}\text { Ética } \\
\text { Cultural } \\
\text { Social }\end{array}$ & $\begin{array}{l}\text { Discussão sobre } \\
\text { os limites para a } \\
\text { prática do futebol. } \\
\text { Trabalho coletivo. } \\
\text { Vivência prática } \\
\text { dos novos jogos. }\end{array}$ & $\begin{array}{l}\text { Bolas, } \\
\text { quadra. }\end{array}$ \\
\hline
\end{tabular}




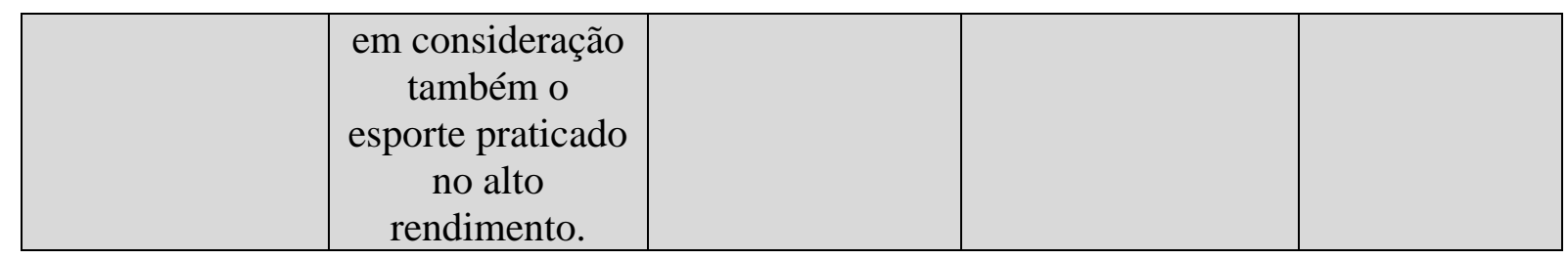

Fonte: elaboração própria com base em Gasparin (2005)

\section{4) SÍNTESE SUPERIOR}

\subsection{Síntese teórica dos alunos ${ }^{4}$ :}

O futebol nasceu na Inglaterra, e é o esporte mais difundido e praticado no mundo, e por isso tem muitos investimentos, tendo grande visibilidade nos meios de comunicação (histórica, conceitual, econômica, e política). O Brasil é considerado o país do futebol, porém, existem inúmeros problemas em nossa sociedade, como a falta de segurança, na saúde não temos um bom atendimento, e na educação as coisas também vão mal. Assistir futebol na televisão é divertido, porém gostaríamos de assistir outros esportes, também (social, cultural, econômica e política). Por isso, gostaríamos que o Brasil fosse mais do que o país do futebol. Em nossa cidade, existem poucas quadras e campos disponíveis e jogamos na rua, com os carros passando. É muito contraditória toda essa situação. Mesmo assim, gostamos de futebol e entendemos que nas aulas de EF todos devem jogar e participar (social, cultural, e ética).

\subsection{Expressão da síntese:}

Elaboração de texto dissertativo em grupo, após o júri escolar.

\section{5) PRÁtica SOCIAL FINAL DO CONTEÚdO}

Tabela 3: Manifestação da nova atitude prática e propostas de ação dos alunos

\subsection{INTENCCÕES DO ALUNO}

Saber mais sobre a história e regras do futebol.

\footnotetext{
${ }^{4}$ Relato tirado das sínteses da atividade do "Júri escolar”. Foi realizada uma síntese final, juntando a ideia das quatro turmas com as quais trabalhamos.
}

\subsection{ACÕES DO ALUNO}

Procurar livros e notícias sobre o futebol. 


\begin{tabular}{|c|c|}
\hline $\begin{array}{c}\text { Praticar em seu cotidiano as variações } \\
\text { aprendidas do futebol nas aulas, e } \\
\text { conhecer mais sobre o rúgbi, e o futebol } \\
\text { americano. }\end{array}$ & $\begin{array}{c}\text { Procurar conhecer mais variações da } \\
\text { modalidade, e procurar espaços } \\
\text { adequados na cidade para sua prática. }\end{array}$ \\
\hline $\begin{array}{c}\text { Colaborar nas aulas de Educação Física, e } \\
\text { respeitar os outros, quanto as } \\
\text { possibilidade de vivência do futebol e } \\
\text { outras modalidades. }\end{array}$ & $\begin{array}{c}\text { Dialogar mais com os colegas, e priorizar } \\
\text { o trabalho coletivo. }\end{array}$ \\
\hline
\end{tabular}

Fonte: elaboração própria com base em Gasparin (2005)

Dessa forma, buscamos ampliar a compreensão dos alunos sobre o tema e, consequentemente, possibilitar-lhes transcender noções cotidianas sobre o futebol. As precárias condições de vida/trabalho, por sua vez, reiteram nosso entendimento de que a luta pela socialização do conhecimento na Educação Física não se esgota no debate pedagógico entre as diferentes concepções, uma vez que engloba, também, a luta pela escola pública, que deve ser enfrentada em sua radicalidade, tal como alerta Saviani (2005, p.257):

O desafio posto pela sociedade de classes do tipo capitalista à educação pública só poderá ser enfrentado em sentido próprio, isto é, radicalmente, com a superação dessa forma de sociedade. A luta pela escola pública coincide, portanto, com a luta pelo socialismo, por ser este uma forma de produção que socializa os meios de produção superando sua apropriação privada. Com isso, socializa-se o saber viabilizando sua apropriação pelos trabalhadores, isto é, pelo conjunto da população.

Constatamos na Pedagogia Histórico-Crítica, que a aprendizagem parte da prática social sincrética dos alunos e que o objetivo após o processo educativo, é que o indivíduo seja capaz de transformar sua realidade. Sendo assim, sua utilização como teoria atinge a realidade concreta dos alunos, tornando a relação entre teoria e prática indissociável, o que se denomina como práxis. Segundo Ghedin (2006):

O processo humano de compreensão-ação é, intrinsecamente, uma dinâmica que se lança continuamente diante da própria consciência de sua ação. Mas a ação, puramente consciente da ação, não realiza em si uma práxis. A consciência-práxis é aquela que age orientada por uma dada teoria e tem consciência de tal orientação. Teoria e prática são processos indissociáveis. Separá-los é arriscar demasiadamente a perda da própria possibilidade de reflexão e compreensão. A separação de teoria e prática se constitui na negação da identidade humana (p.133). 
Portanto, processo ensino-aprendizagem se torna um espaço gerador e produtor de conhecimento, mas isso não é possível sem uma sistematização que passa por uma postura crítica do educador sobre as próprias experiências. Refletir sobre os conteúdos trabalhados, as maneiras como se trabalha, a postura frente aos educandos, frente ao sistema social, político, econômico e cultural é fundamental para se chegar à produção de um saber fundado na experiência.

Deste modo, o conhecimento que o educador "transmite" aos educandos não é somente aquele produzido por especialistas deste ou daquele campo específico de conhecimento, mas ele próprio se torna um especialista do fazer (teórico-prático-teórico). Fundar e fundamentar o saber docente na práxis (ação-reflexão-ação) é romper com o modelo "tecnicista mecânico" da tradicional divisão do trabalho e impor um novo paradigma epistemológico capaz de emancipar e "autonomizar" não só o educador, mas, olhando-se a si e à própria autonomia, possibilitar a autêntica emancipação dos educandos, não sendo mais um agente formador de mão-de-obra para o mercado, mas o arquiteto da nova sociedade, livre e consciente de seu projeto político.

\section{CONSIDERAÇÕES FINAIS}

A partir da organização, sistematização e preparo do conteúdo do futebol nas aulas de EF, junto aos alunos $6^{\circ}$ ano do Ensino Fundamental, defendemos que o trato com o conhecimento não pode e nem deve ser conduzido de qualquer maneira. As aulas de EF pautadas na transformação didático-pedagógica do esporte entre outros conteúdos, e na participação ativa dos alunos, contribuem para a transposição de um modelo tradicional e tecnicista de ensino, caminhando rumo à legitimidade na formação humana dos alunos.

Sendo assim, faz-se necessário dialogar com as teorias do campo educacional, como no caso, a Pedagogia Histórico-Crítica. Torna-se uma oportunidade rica de confrontarmos a realidade escolar, buscando através dos desafios e da especificidade da escola crescer como profissionais e seres humanos. O preparo sistematizado das aulas, as reflexão acerca do planejamento, e a reflexão conjunta na prática docente, permitem através das pedagogias críticas, a busca de uma prática pedagógica consciente e comprometida com a transformação social. Para tanto, faz-se necessário o comprometimento com a prática docente, e no devido caso, não podemos negligenciar a 
formação dos alunos. Dessa forma, justificamos o trabalho junto aos alunos, através de uma prática problematizadora pautada nos elementos da cultura corporal.

\section{REFERÊNCIAS}

BETTI, M.; FERRAZ, O. L.; DANTAS, L. E. P. B. Educação Física Escolar: estado da arte e direções futuras. Rev. bras. Educ. Fís. Esporte, São Paulo, v.25, p.105-15, dez. 2011.

BRACHT, V. Educação Física e aprendizagem social. 2ed. Porto Alegre: Magister, 1997.

CHAUÍ, M. Convite à filosofia. São Paulo: Ática, 1995.

COLETIVO DE AUTORES. Metodologia do ensino de Educação Física. São Paulo: Cortez, 1992.

DUARTE, N. Luta de classes, educação e revolução. In: SAVIANI, D; DUARTE, N. (orgs.) Pedagogia histórico-crítica e luta de classes na educação escolar. Campinas: Autores Associados, 2012. p.149-166.

DUTRA, G. C. Z; MORAES, F. C. T. Formação de professores de educação física: uma disputa entre projetos de formação humana. Texto disponível em: $<$ http://www.vanessanogueira.info/sifedoc/Anais/Eixo\%2007/Geovanna\%20Caroline\% 20Zanini\%20Dutra.pdf > Acesso em 24 de julho de 2013.

GHEDIN, E. Professor reflexivo: da alienação da técnica à autonomia crítica. In: PIMENTA, S. G; GHEDIN, E. (orgs.) Professor reflexivo no Brasil: gênese e crítica de um conceito. São Paulo: Editora Cortez, 2005. p.129-150.

GASPARIN, J. L. Uma didática para a Pedagogia histórico-crítica. Campinas: Autores Associados, 2005.

GOLDENBERG, M. A arte de pesquisar: como fazer pesquisa qualitativa nas Ciências Sociais. 10a ed. Rio de Janeiro, Record, 2007.

HURTADO, J. G. G. M. O ensino da Educação Física: uma abordagem didática. 2. ed. Curitiba, Paraná. Educa/Editer, 2003.

MEDINA, J. P. S. A Educação Física cuida do corpo e... "mente": Bases para a renovação e transformação da Educação Física. Campinas: Papirus, 1990.

SAVIANI, D. Escola e democracia. 33. ed. São Paulo: Autores Associados, 2003. 
Formação de professores: aspectos históricos e teóricos do problema no contexto brasileiro. Revista Brasileira de Educação, v. 14, n. 40, p.143-155, jan./abr. 2009.

Formação docente no Brasil: dilemas e perspectivas. Poíesis Pedagógica - V.9, N.1 jan/jun.2011; pp.07-19.

Pedagogia Histórico-Crítica: primeiras aproximações. 11. ed. Campinas: Autores Associados, 2012.

; DUARTE, N. (orgs.) Pedagogia histórico-crítica e luta de classes na educação escolar. Campinas: Autores Associados, 2012.

TAQUES, M. F. et al. O papel do pedagogo na gestão: possibilidades de mediação do currículo. In: IX Congresso Nacional de Educação - EDUCERE, 2009, Curitiba. Anais do Evento. Curitiba: PUCPR, 2009. CD-ROM. p. 3169-3181.

\section{AUTORES:}

\section{José Jairo Vieira}

Doutor em Sociologia pelo Instituto Universitário de Pesquisa do Rio de Janeiro (IUPERJ). Mestre em Sociologia do Esporte pela Universidade doestado do Rio de Janeiro (UREJ). Sociólogo pela Universidade Federal do Rio de Janeiro (UFRJ). Licenciado em Educação Física pela Universidade do Estado do Rio de Janeiro (UERJ). Coordenador do Laboratório de Pesquisa em Desigualdade e Diversidade de Corpo, Raça e Gênero (LADECORGEN) da Universidade Federal do Rio de Janeiro (UFRJ). Docente do Programa de Pós-Graduação em Educação (PPGE) e do Programa de Pós-Graduação em História Comparada (PPGHC), ambos da Universidade Federal do Rio de Janeiro (UFRJ)

\section{Fernando Paulo de Lima}

Doutor em Educação pela Universidade Federal do Rio de Janeiro (UFRJ); Mestre em Educação pela Universidade Federal de Viçosa (UFV); Licenciado e Bacharel em Educação Física pela Universidade Federal de Viçosa (UFV). Pesquisador do Laboratório de Pesquisa em Desigualdade e Diversidade de Corpo, Raça e Gênero (LADECORGEN) da Universidade Federal do rio de Janeiro (UFRJ). Professor de Educação Física no Ensino Fundamental das séries iniciais na Secretaria Municipal de Educação (SME) do Munícipio do Rio de Janeiro.

\section{Shirléia dos Santos Peixoto}

Mestranda em Políticas Públicas e Direitos Humanos no Núcleo de Estudos de Políticas Públicas em Direitos Humanos (NEPP-DH) da Universidade Federal do Rio de Janeiro 
(UFRJ). Pedagoga pela Universidade Federal do Rio de Janeiro. Advogada pelo Centro Universitário Augusto Motta (UNISUAM). Pesquisador do Laboratório de Pesquisa em Desigualdade e Diversidade de Corpo, Raça e Gênero (LADECORGEN) da Universidade Federal do rio de Janeiro (UFRJ). Diretora Adjunta de uma escola na Secretaria Municipal de Educação (SME) do Munícipio do Rio de Janeiro.

Recebido em: 15/12/2021

Aprovado em: 18/01/2022

Publicado em: 23/01/2022 